\title{
Designing Value-Oriented Service Systems by Value Map
}

\author{
Arash Golnam ${ }^{1}$, Vijay Viswanathan ${ }^{2}$, Christa I. Moser ${ }^{3}$, \\ Paavo Ritala ${ }^{4}$, and Alain Wegmann ${ }^{1}$ \\ ${ }^{1}$ School of Computer and Communication Sciences, \\ Ecole Polytechnique Fédérale de Lausanne, Lausanne, Switzerland \\ \{arash.golnam, alain.wegmann\} @epfl.ch \\ ${ }^{2}$ Webdoc, \\ Rue de Genève 17 Lausanne, 1003, Switzerland, Switzerland \\ vviswanathan@gmail.com \\ ${ }^{3}$ Business School Lausanne, \\ Route de la Maladière 21, 1022 Chavannes, Switzerland \\ christa.moser@bsl-lausanne.ch \\ ${ }^{4}$ School of Business, Lappeenranta University of Technology, \\ Lappeenranta, Finland \\ paavo.ritala@lut.fi
}

\begin{abstract}
In this paper, we introduce a problem structuring method (PSM) called "Value Map". Value Map is an extension to the Supplier Adopter Relationship Diagram in the Systemic Enterprise Architecture Method (SEAM). Value Map assists in understanding, analysis and design of value creation and capture in service systems. We illustrate the applicability of the Value Map by modeling value creation and capture in the service system of a social networking company called Webdoc. To validate the usefulness of the Value Map, we conducted an empirical study in which we also compared the Value Map to Business Model Canvas, one of the most established methods in business model design. The results of the study show that the Value Map helps business practitioners in understanding and analyzing customer value, customer value creation, and the value capture processes. We conducted an empirical study in which we assessed the usefulness of Value Map and compared it with Business Model Canvas, one of the most established methods in business model design. The results of the study show that the Value Map helps business practitioners to understand and analyze customer value, customer value creation, and the value capture processes.
\end{abstract}

Keywords: Modeling, Problem Structuring Method (PSM), SEAM, Service Systems, Value Creation and Capture, Value Map.

\section{Introduction}

In the theories of economic exchange, value was traditionally viewed only from the perspective of monetary transactions between the customers and the organization. Value was perceived to be rooted in goods that were produced by the organization. Once distributed to customers, the value produced was destroyed, or consumed. In the 
marketing literature, this perspective is broadly referred to as the Goods-Dominant (G-D) logic, which was prevalent pre-1900s. From the standpoint of the G-D logic, customers played a negligible role in the value creation process. In other words, the organization created what was perceived as valuable to the customer [1] without the involvement of the customer. The underlying objective of the G-D logic is to "maximize operational efficiency and reduce firm costs in order to increase financial profits". Moreover, G-D logic primarily focuses on operand resources (i.e., those resources that are tangible; physical goods) that are manifested in products [2].

In a paradigm shift, the economic exchange model has been augmented and extended to include customers as a fundamental tenet of the value creation process. This shift has led to the emergence of the Service-Dominant (S-D) logic. The G-D and the S-D logic differ in a number of important ways, (see Table 1).

Table 1. G-D Logic vs. S-D Logic

\begin{tabular}{|l|l|l|}
\cline { 2 - 3 } \multicolumn{1}{c|}{} & \multicolumn{1}{c|}{ G-D Logic } & \multicolumn{1}{c|}{ S-D Logic } \\
\hline Focus & $\begin{array}{l}\text { Operand resources; creating goods to be } \\
\text { sold }\end{array}$ & $\begin{array}{l}\text { Operant resources; intangible resources (i.e., } \\
\text { knowledge and skills) }\end{array}$ \\
\hline Goods & The product of value to be exchanged & Seen as intermediaries in service delivery \\
\hline Service & Intangible output of a good & Service is the foundation of all exchange \\
\hline Value & Created within organizations & Co-created by organizations and customers \\
\hline
\end{tabular}

The focus in the S-D logic is on intangibles, competencies, dynamic exchange processes and relationships that are broadly referred to as operant resources. Operant resources have an influence on other resources to create benefit through the service [2].The concept of a good in the G-D logic is the product of value to be exchanged. While, in the S-D logic, a good is merely seen as an intermediary in the delivery of service, broadly viewed as delivery mechanisms for services [3].Furthermore, in the S-D logic, the concept of service is extended beyond a "particular" kind of intangible good (i.e., knowledge and skills) or an intangible output of a good. Instead, service is deemed as the foundation of all exchange (i.e., service exchanged for service) [4]. Finally, the S-D perspective conceptualizes a firm's offerings not as an output, but as an input for the customer's value-creation process. Thereby, instead of viewing value as being created within companies, value is increasingly viewed as being co-created between companies, customers, and other actors within a service system.

Service systems are the arrangement of resources, including people, information, and technology [5]. In service systems, value is perceived as being created in collaboration with the customer. Authors in [6 - 9] argue that in the S-D logic, the supplier is not the sole creator of value, but that value emerges when the customer is involved in the process. Thus, from the S-D standpoint, customers are the eventual locus and the determining party of the value that is created [10]. Authors in [11] suggest that the customer's collaborative role in value creation is what is known as co-creation of value. 
Moreover, the S-D logic emphasizes on the subjective and experiential nature of value and thus asserts that value is "uniquely and phenomenologically determined by the beneficiary [3]. Based on this perspective, a distinction is made between value-inuse and value-in-exchange. Value-in-use refers to the specific qualities of the service. These qualities are perceived by users in relation to their needs (i.e., speed or quality of performance, aesthetics, or performance features). Value-in-exchange can be defined as the "monetary amount realized at a certain point in time in exchange" [12]. After value has been created, it is important for the organization to capture this value. Authors in [12] explain that some value may be lost or in some cases, shared with other stakeholders. Value capture, also termed value retention or value appropriation, deals with the amount of exchange value the customer has kept and retained by the organization in the form of profit [13]. From a non-monetary perspective, value capture can be described as the degree to which service quality goals have been met or exceeded [14].

Once value has been (co)-created, the viability of the service system depends on its ability to capture the created value. In other words, the service provider sustains its existence with the value it retains [15]. Thus, it can be asserted that sustainable value (co)-creation and capture is an imperative for viability of service systems. In the service science literature, a number of modeling frameworks provide conceptual tools to support the design of service offerings (see for instance [16-20]). Such modeling frameworks, however, mainly address the design and analysis of value from the customers' perspective and do not sufficiently address service providers' value capture in the service value equation. In general, the same gap can be broadly identified in the service literature, where value (co)-creation has often been emphasized over value capture.

Moreover, there are nonlinearities and feedback structures inherent in the interplay between value creation and capture in service systems. For instance, a slight increase in price, results in the loss of a huge proportion of the market, or, a new service feature can boost the customer base of a service provider. While presenting both conceptual and practical challenges for service providers and service science researchers, this systemic interconnectedness has been glossed over in the service science research.

To tackle the above mentioned research gaps, in this study, we introduce the Value Map; a framework for modeling value in service systems that takes into account both value creation (for and with customers) and value capture (by service providers). The Value Map can be broadly referred to as a problem structuring method (PSM) [21-23] that aims to provide conceptual and practical assistance in analyzing, reconfiguring and designing value in service systems. The modeling constructs and notational elements in the Value Map are derived from a literature review we conducted to gain a new perspective into the structure and the dynamics of value creation and capture.

This paper is organized in the following way. In Section 2, we elaborate on the structure and the results of the literature review we conducted to discover the important concepts relevant to value creation and capture. In order to gain a better 
understanding, the concepts and their relationships were formalized in 10 algebraic functions and were graphically represented in form of a conceptual model. In Section 3 , we introduce the value map and its modeling constructs and notational elements. In Section 4, we present the results of the application of the Value Map to model and improve value creation and capture in a social networking platform called Webdoc. Section 5 includes the related work. In Section 6, we briefly report on the results of an empirical study we conducted to assess the usefulness of the Value Map and to compare it to Business Model Canvas [24] an established method for presenting and designing business models. Finally, in Section 7 we present our conclusions, limitations of research and our future work.

\section{The Conceptual Model}

In this section, we present the structure and the results of the literature review we conducted on the theoretical frameworks that examine value creation and capture. A literature review can be conducted for a variety of purposes see [25] In this paper, the literature review will help us discover the important concepts relevant to value creation and capture and explore the relationships among these concepts in order to gain a new perspective into the structure and the dynamics of value creation and capture. Thus, the literature review helps us understand the "what" (i.e., the concepts), the "how", (i.e., their relationships) and the "why" (i.e., the rationale behind the selection of the concepts and the perceived relationships among them). According to [26], the "what", "why" and the "how" are the three tenets of a theoretical contribution.

The correct selection of the published materials is a vital element of a literature review. We followed the methodology in [27] and developed a number of criteria for selection of the work to be included in the literature review. The articles we included in the literature review addressed value creation and capture simultaneously, and were indexed by Institute for Scientific Information (ISI). These two criteria led us to a total of around 30 articles. We then derived the key concepts discussed in each article. The concepts were then analyzed and divided into three categories: customer value, customer value creation process, and service provider value capture. Next, for each category, we developed a number of functions that embody algebraic expressions explaining the relationships between the concepts (see Table 2). Having identified the concepts and their relationships, we graphically represented them in form of a conceptual model made up of boxes (i.e., the concepts) and arrows (i.e., their relationships), (see Figure 1). According to [26], "such visual representations often clarify the author's thinking and increase the reader's comprehension". As illustrated in Figure 1, we have marked the three categories of concepts in the conceptual model. 
Table 2. The Algebraic Functions capturing relationships between Customer Value, Customer Value Creation Process, and Service Provider Value Capture concepts

\begin{tabular}{|c|c|c|}
\hline \multirow{4}{*}{ 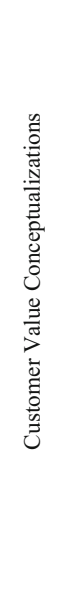 } & 1 & $\begin{array}{l}\text { Net perceived customer value }(\mathrm{NPCV})=\text { (perceived service benefits) }- \text { (perceived service costs) } \\
N P C V \text { equals the benefits minus the costs of receiving the service. }\end{array}$ \\
\hline & 2 & $\begin{array}{l}\text { Perceived benefits of the service offering }=\text { (perceived functional benefits) }+ \text { (perceived emotional } \\
\text { benefits) } \\
\text { The sum of the functional and emotional benefits constitutes the perceived benefits of the service } \\
\text { offering. } \\
{[28,31]}\end{array}$ \\
\hline & 3 & $\begin{array}{l}\text { Perceived costs of the service offering }=\text { (Perceived non-monetary costs) }+ \text { (Perceived monetary } \\
\text { costs) } \\
\text { The costs incurred to the customer who receives the service are divided into two categories: monetary } \\
\text { cost and non-monetary costs that can include time, energy, and psychic costs. } \\
{[13,28]}\end{array}$ \\
\hline & 4 & $\begin{array}{l}\text { Relative NPCV of the service offering }=(\mathrm{NPCV} \text { of the service provider's value network offering) - } \\
\text { (NPCV of the competing value network's service offering) } \\
\text { Relative net perceived customer value is the net perceived value created by a service provider's } \\
\text { offering in relation to the competing offerings. }\end{array}$ \\
\hline \multirow{2}{*}{ 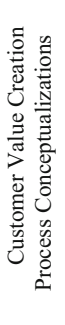 } & 5 & $\begin{array}{l}\text { Service components } \subset \text { Resources and capabilities (of the service provider and its value network) } \\
\text { Service components are a subset of the resources and capabilities of the service provider and its value } \\
\text { network that are manifested in the service. } \\
{[13,32-33]}\end{array}$ \\
\hline & 6 & $\begin{array}{l}\text { Service components (of service provider and its value network) } \Rightarrow \text { Service features } \Rightarrow \text { Service value } \\
\text { attributes (of service customer) } \\
\text { Service components create some emergent properties for the service, which are noticed by the } \\
\text { customer. We refer to these emergent properties of the service as service features. Service features } \\
\text { impact the perceived customer value through various value attributes. }\end{array}$ \\
\hline \multirow{4}{*}{ 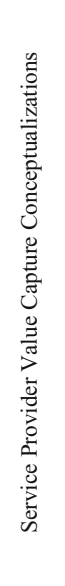 } & 7 & $\begin{array}{l}\text { NPCV of the service offering } \propto \text { Service providers benefits } \\
\text { The customer's relative perception of value determines the actions the customers undertake, which } \\
\text { result in generating more or less benefits for the service provider. }\end{array}$ \\
\hline & 8 & $\begin{array}{l}\text { Net captured value }(\mathrm{NCV}) \text { of the service provider }=(\text { Value captured by the service provider }) \\
-(\text { Cost of the service components }) \\
\text { The NCV is the value captured by the service provider minus the costs of the service components. }\end{array}$ \\
\hline & 9 & $\begin{array}{l}\text { (Non-)monetary benefits for the service provider } \propto \text { Value captured by the service provider } \\
\text { The (non)monetary benefits created by the customer for the service provider are proportional to the } \\
\text { value captured by the service provider. } \\
\text { [35-37] }\end{array}$ \\
\hline & 10 & $\begin{array}{l}\text { Costs of the service components }=(\text { Organizing costs i.e. internal costs of the service provider) }+ \\
\text { (Opportunity costs i.e. external costs of the suppliers in service provider value network) } \\
\text { The costs of the service components equal the sum of the organizing costs of the service provider, and } \\
\text { the external opportunity costs of the suppliers in the value network. }\end{array}$ \\
\hline
\end{tabular}




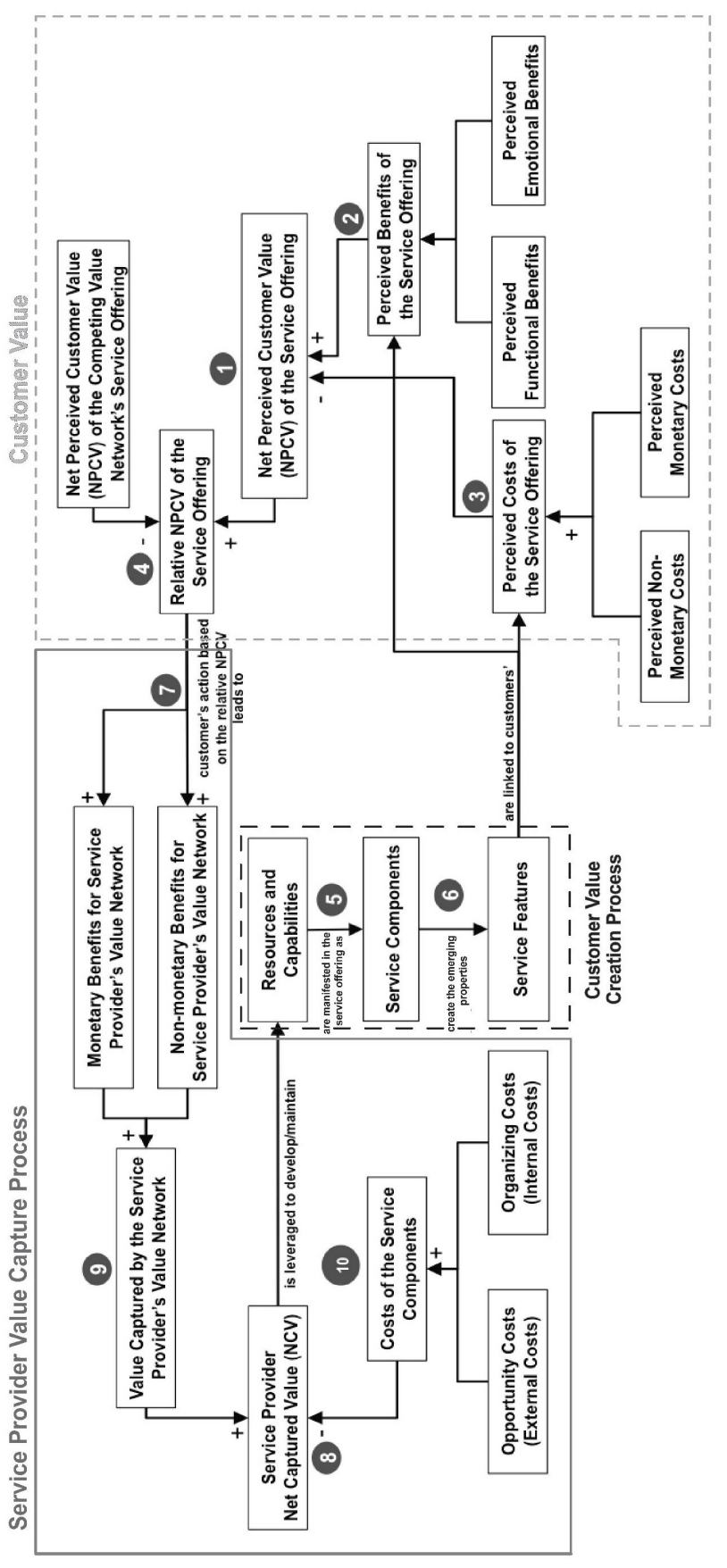

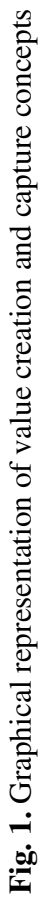




\section{The Value Map}

Figure 2 represents the actors and their properties in a service system. We refer to this representation as the Service System Model. As illustrated, the Service System is composed of a Service Provider Value Network and Service Customer A and B. The Service Provider Value Network can be represented as a black-box or a white-box denoted respectively by grey and white colors. In Figure 2, [w], [c] denote whole (black- box) and composite (white-box) representations of the systems and entities. When represented as a black-box we model the Service, the Service Features, and the (Non)monetary Benefits for the Service Provider Value Network as its emergent properties. The white-box view of the Service Provider Value Network provides insight into the configuration of the value network. Thus, we will be able to view the organizations or the people who compose the value network and their contribution to the service in terms of the Service Components they provide. We can also see the Value Captured by each of the entities in the value network. As illustrated in Figure 2, the Service Provider collaborates with Organizations A and B and the Developer to create the Service. This collaboration is captured in terms of the Service Components each of these entities provides. Finally, in the Service System Model we represent the Service Customers by modeling the Attributes that impact their perception of the service value and the Actions the customers take on the basis.

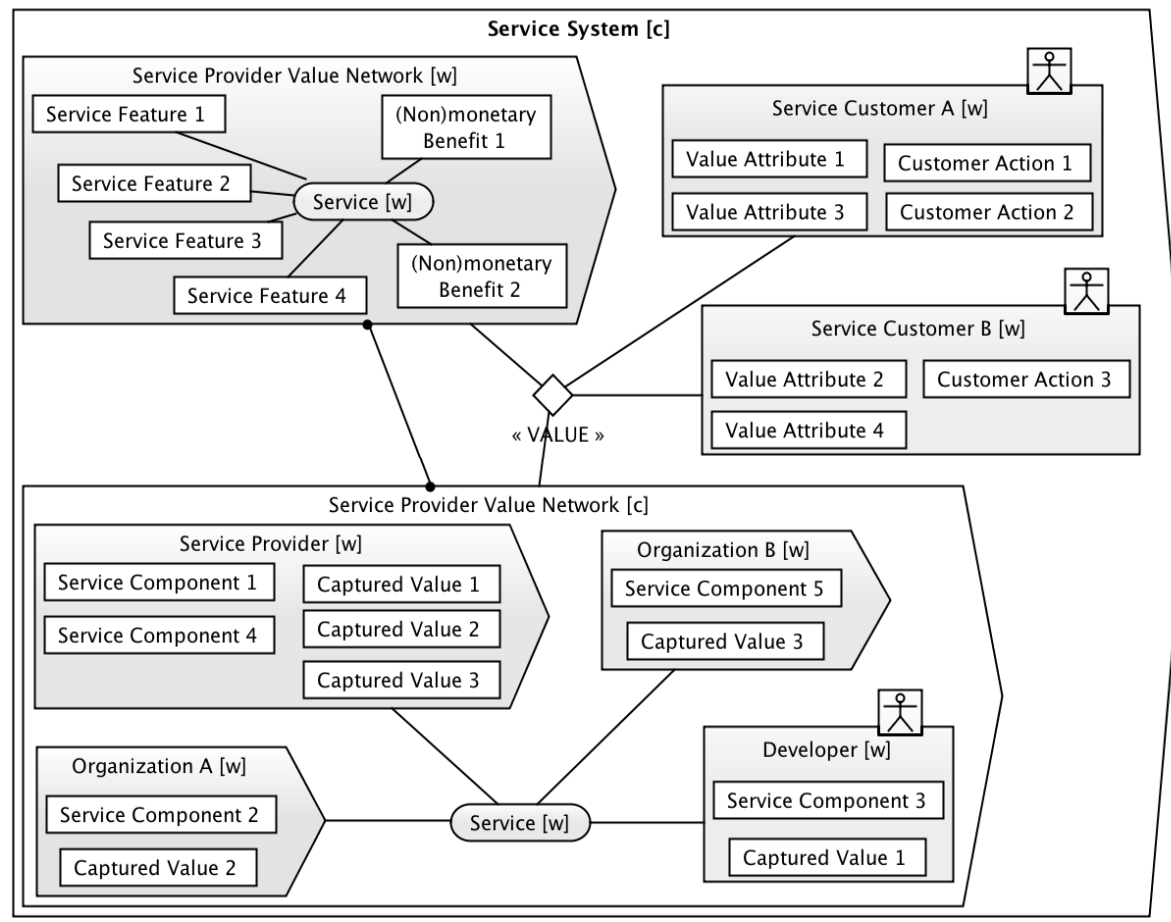

Fig. 2. Service System Model 
A generic Value Map is illustrated in Figure 3. As marked in Figure 3, the Value Map embodies customer value, customer value creation and service provider value capture processes (i.e., the three categories of concepts presented in Section 2) in a service system. This is achieved by making the relationships between the actors (i.e., service provider, organizations in the value network, service customer, etc.) and the properties (service components, service features, value attributes, customer actions, etc.) presented in the Service System Model explict. In Table 3, we explain the relationships and their notation in the Value Map.

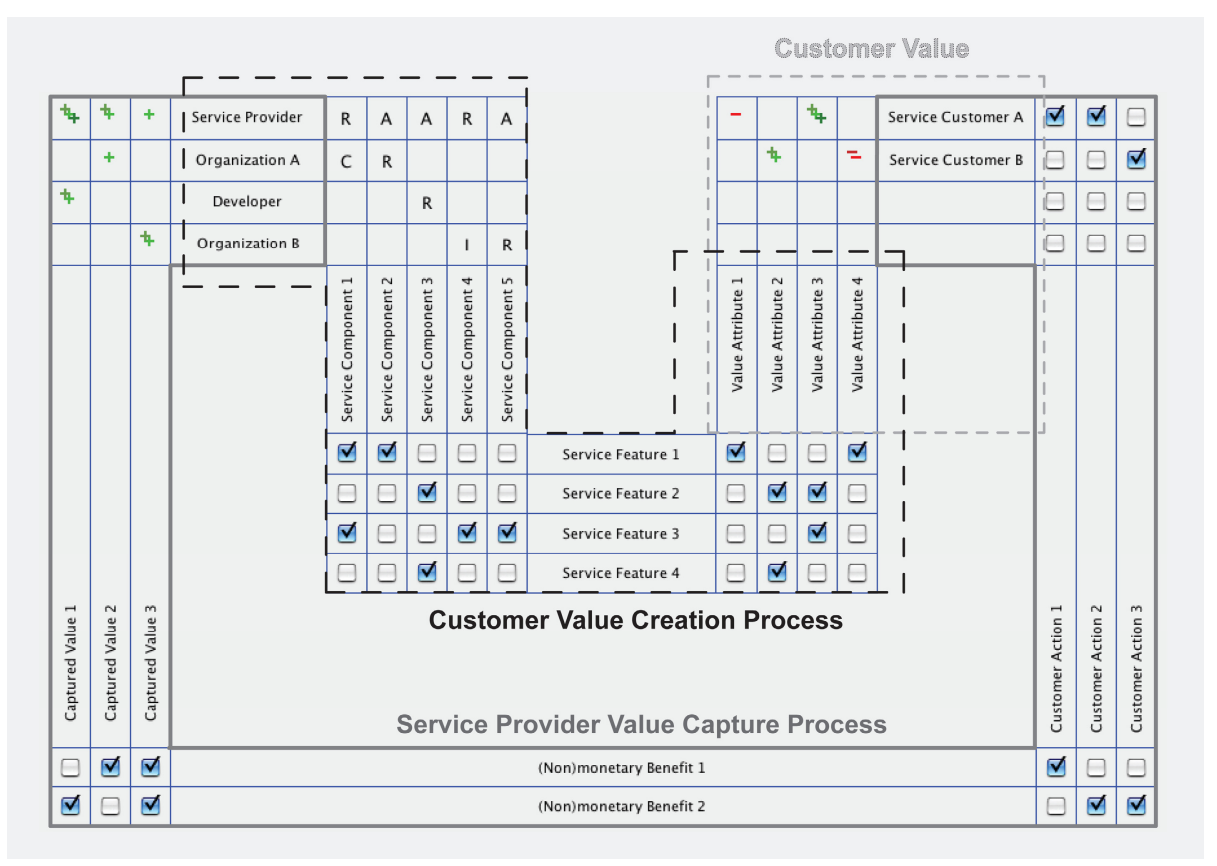

Fig. 3. The Value Map

To map the Service Provider and the other entities in the Service Provider Value Network to the Service Components we use the RACI (Responsible, Accountable, Consulted, Informed) Matrix. As illustrated in Figure 3, the Service Provider is responsible for Service Component 1 and consults Organization A. This consultation may reduce the risk of incompatibility between the Service Components 1 and 2 or ensure the existence of a contingency plan in case an unanticipated scenario arises in the value creation process. The Service Provider also contributes to the service through Service Component 4. Here, the Service Provider makes sure that Organization $B$ is kept informed about the progress. The Service Component 4 provided by Organization $B$ may be affected by Service Component 5 which is provided by the Service Provider. Note that these two service componets create the Service Feature 3. This sheds light on why Organization B needs to be kept up-todate. In principle, the Service Provider is accountable for correct and thorough provisioning of the service components for which other entities are responsible. 
Table 3. Relationships and mappings in the Value Map

\begin{tabular}{|l|c|}
\hline \multicolumn{1}{|c|}{ Relationship } & Mapping Notation \\
\hline $\begin{array}{l}\text { - Entities in the value network } \\
\text { - Service Components }\end{array}$ & RACI Matrix \\
\hline $\begin{array}{l}\text { - Service Components } \\
\text { - Service Features }\end{array}$ & $\square$ \\
\hline $\begin{array}{l}\text { - Service Features } \\
\text {-Value Attributes }\end{array}$ & $\square$ \\
\hline $\begin{array}{l}\text {-Value Attributes } \\
\text { - Net Perceived Customer Value }\end{array}$ & +++ Strong Positive \\
\hline $\begin{array}{l}\text { - Customer } \\
\text { - Customer Actions }\end{array}$ & $\square$ \\
\hline $\begin{array}{l}\text { - Customer Actions } \\
\text { - (Non)monetary Benefits }\end{array}$ & $\square$ \\
\hline $\begin{array}{l}\text { - (Non)monetary Benefits } \\
\text { - Captured Value }\end{array}$ & $\square$ \\
\hline $\begin{array}{l}\text { - Captured Value } \\
\text { - Service Provider's Net Captured Value }\end{array}$ \\
\hline
\end{tabular}

As discussed in the previous section, Service Components create the Service Features that impact the net perceived customer value (NPCV) through the Value Attributes. Based on his or her perception of the value of the service offering, the customer takes Actions. These Actions generate the (Non) monetary Benefits for the Service Provider Value Network. These benefits are directly linked to the Value Captured by each of the entities in the value network. In Figure 3, the Service Provider and Organization A provide Service Components 1 and 2 respectively. These two components will create the Service Feature 1 that negatively impacts the NPCV for Service Customer A and B through Value Attributes 1 and 4. As shown, the impact is stronger for the Service Customer B. Similarly, the Service Provider and Organization $B$ provide Service Components 4 and 5 respectively, thereby creating Service Feature 3. This service feature has a strong positive impact on the Service Customer A's perception of the service value as captured in Value Attribute 3. Service Customer A takes Customer Actions 1 and 2 that contribute to the (Non) monetary Benefits 1 and 2 thereby realizing and contributing to Captured Value $1-3$ for the entities in the Service Provider Value Network. As shown, Captured Value 1 has a strong and medium positive impact on the net captured value of the Service Provider and Developer respectively. Other sections of the Value Map can be interpreted the same way.

\section{Modeling Value Creation and Capture in Webdoc}

In this section, we report on the application of the Value Map as a diagnostic tool to improve value creation and capture in the service system of Webdoc. First we present some information about Webdoc and the motivations underlying the project in which the Value Map was applied. Next, we discuss how customer value attributes were surfaced by means of the data capture and user intelligence tools. Then, we model the creation and capture of value in Webdoc using the Value Map. Finally, we present some strategy implications based on the findings from our modeling process. 


\subsection{Webdoc}

Webdoc is an Internet startup founded in Lausanne in 2009. It currently has offices in Lausanne (headquarters: management, engineering, design, and product), London (business development), Lima (community engagement and support), and San Francisco (business development). Webdoc provides a social network platform on which users can express themselves in a richer, more interactive way than traditional social networks. Specifically, it provides a channel in which existing web content, be it video, audio, images, or text, can be combined with content created using the proprietary rich editor, in a way that requires no technical skills and is easy to share and distribute. These creations are referred to as "webdocs" and can be embedded on any third-party site, including other websites and social networks. Additionally, all webdocs created can be showcased in their relevant category of interest on the Webdoc destination site. The creators have the option to make their webdocs completely private (only users granted explicit permission can view) or public but unlisted (meaning the webdoc will not be featured on the Webdoc site). The service is free to all users with no advertising, currently available in 5 languages (English, French, Spanish, Portuguese, and Russian), and accessible through a variety of platforms including desktop web browsers, mobile device browsers, and native mobile applications.

As the company and user base has grown tremendously in the past 12 months, there has been an increasing need for establishing a better understanding of and improving perceived customer value. The analysis, conception, and subsequent improvement of the value perceived by the customers feed into vital functions of the service and company, including product development, overall strategy, valorization of the company for current and future investment rounds, and optimization of the service. These needs are what triggered the work that has led to the culmination of this project. In the next sections we explain how the value attributes were surfaced and how Value Map improved value creation and capture in Webdoc's service system.

\subsection{Surfacing Customer Value Attributes}

One of the main challenges in modeling value creation and capture in service systems is surfacing the customer value attributes. This is considered as an important initial step to gain insights into the customers' perceived benefits and costs of adopting the services offered by a service provider. In the context of the project conducted at Webdoc, this step was further sub-divided into two distinct but strongly interconnected fields: data capture and user intelligence.

\subsubsection{Data Capture}

Broadly speaking, information on customers' perceptions of value and their relative importance can be gathered through direct interaction with customers or 
customer surveys. Revealed preference methodologies [40] are also used to understand customers' needs and preferences based on their behavior. However, for Internet-based services, the channels through which the service provider can understand its users are very different than those of a traditional service. The overwhelming difference is the radically new interaction paradigm through which service providers and service adopters communicate. For traditional service providers, a wealth of customer data, such as customer demography, is gathered without any explicit effort, simply by the customer's physical presence. On the other hand, for an Internet firm like Webdoc, sophisticated measures need to be put in place to understand even the most fundamental characteristics of its users, such as location, language, gender, and age. Without the application of data capture tools it would almost be impossible to answer basic questions such as "Who are the service customers?" "How frequently do they use the service?" "How do service customers access the service?" "How much do they use the service for?" To answer such questions, a number of service providers offer web analytics packages. These are third party, off-the-shelf solutions that can be customized to varying degrees, and are provided for a cost ranging from free to tens of thousands of dollars a month. There also exists the possibility for every Internet company to custom-build its own web analytics and data capture solution. In the context of this project, the latter was the first solution considered, but was quickly discarded due to its infeasibility.

\subsubsection{User Intelligence}

Data capture contributes to the decision processes in Internet-based services by providing macro-level information. User intelligence tools, however, provide a much more nuanced perspective at the micro level, which sacrifices on breadth of data for depth. The fundamental motivation of the application of user intelligence was the need for product development insight. While numeric metrics such as overall visitors, logged in users, views of a particular page, and so on are certainly invaluable, they are more useful in measuring the effectiveness (or ineffectiveness) of a feature postchange than they are in suggesting what changes might be needed in the first place. Thus, user intelligence provides data that is more prescriptive. This data is complementary to the descriptive data derived from the data capture tools.

User intelligence applications offer various analytical and intelligence tools such as heat maps and user recordings. Heat maps are screenshots of the website showing the spatial distribution of clicks over the screen space that offer important product insight, as they show what links and content garner the highest level of attention from the audience. User recordings are an attempt to recreate individual user sessions by aggregating mouse movement, keyboard activity, scrolling and navigation, and clicks into a video.

Some advanced user intelligence applications provide the possibility of creating a test environment in which a random sample of participants execute tasks that are predefined based on the demographic and technical requirements. Upon completion of the tasks, a questionnaire is automatically generated, which is filled out by the 
participant. The key aspect is that while performing the tasks, the entire user screen is recorded, along with an audio stream for the live commentary of the participants. The application of data capture and user intelligence tools provided invaluable assistance in surfacing the customer value attributes.

\subsection{Modeling Value Creation and Capture in Webdoc}

In this section, we apply the Value Map to represent value creation and capture in Webdoc's service system. To this end, first we shed some light on how Webdoc can capture value as a service provider. Next, we analyse the value for Webdoc's customers. Finally, we show how the Value Map resulted in improving value creation and capture in Webdoc.

\subsubsection{Value Capture by Webdoc}

Internet-based companies, in particular, social networking platforms such as Webdoc follow a free business model [24] this means these companies do not charge the customers for service they offer. Thus, to sustain their existence these service providers rely solely on the non-monetary benefits from their customers. These nonmonetary benefits in the case of Webdoc include: number of users, volume of activity per user, and time spent on the platform per user. Such non-monetary benefits can result in value capture for Webdoc by:

- Increasing the valuation of the company in case of an initial public offering (IPO) or acquisition. As an example, Instagram, the online photo sharing service provider, was acquired by Facebook in April 2012 for $\$ 300$ million in cash and 23 million shares of common stock. The deal was worth $\$ 1$ billion at the time. Before the acquisition, Instagram announced that more than 5 billion photos had been shared through its mobile apps [41].

- Securing funding by venture capitalists (VCs). Most start-ups rely on funds from external sources such as VCs [42]. The non-monetary benefits listed above are among the determining factors for VCs to make a decision to invest or to continue investing in a start-up company like Webdoc.

- Monetization through advertisement. Another possibility for Internet-based services is generating revenues by authorizing the presence of advertisements on their webpages. Advertisement-based monetization is one of the main revenue streams for internet-based service providers. The number of visitors, their activity volume and the time they spend on a website are the main criteria for businesses or individuals to choose a website on which they place their advertisements.

\subsubsection{Value for Webdoc's Customers}

To improve the NPCV, first an understanding of different customer categories of Webdoc needs to be established. Two main categories of customers are identified: first-time and return visitors. When a first-time visitor uses Webdoc's services again, he becomes a return visitor. 


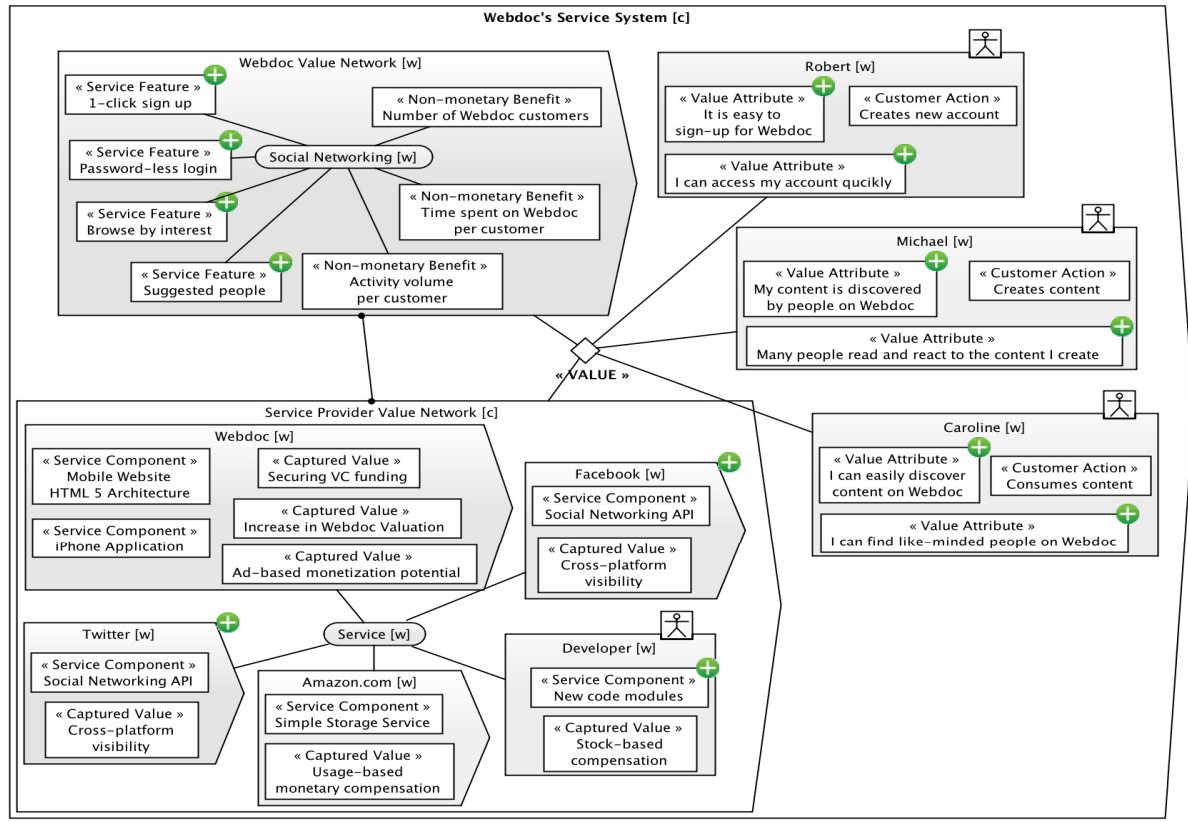

Fig. 4. Webdoc's service system, new actors and properties

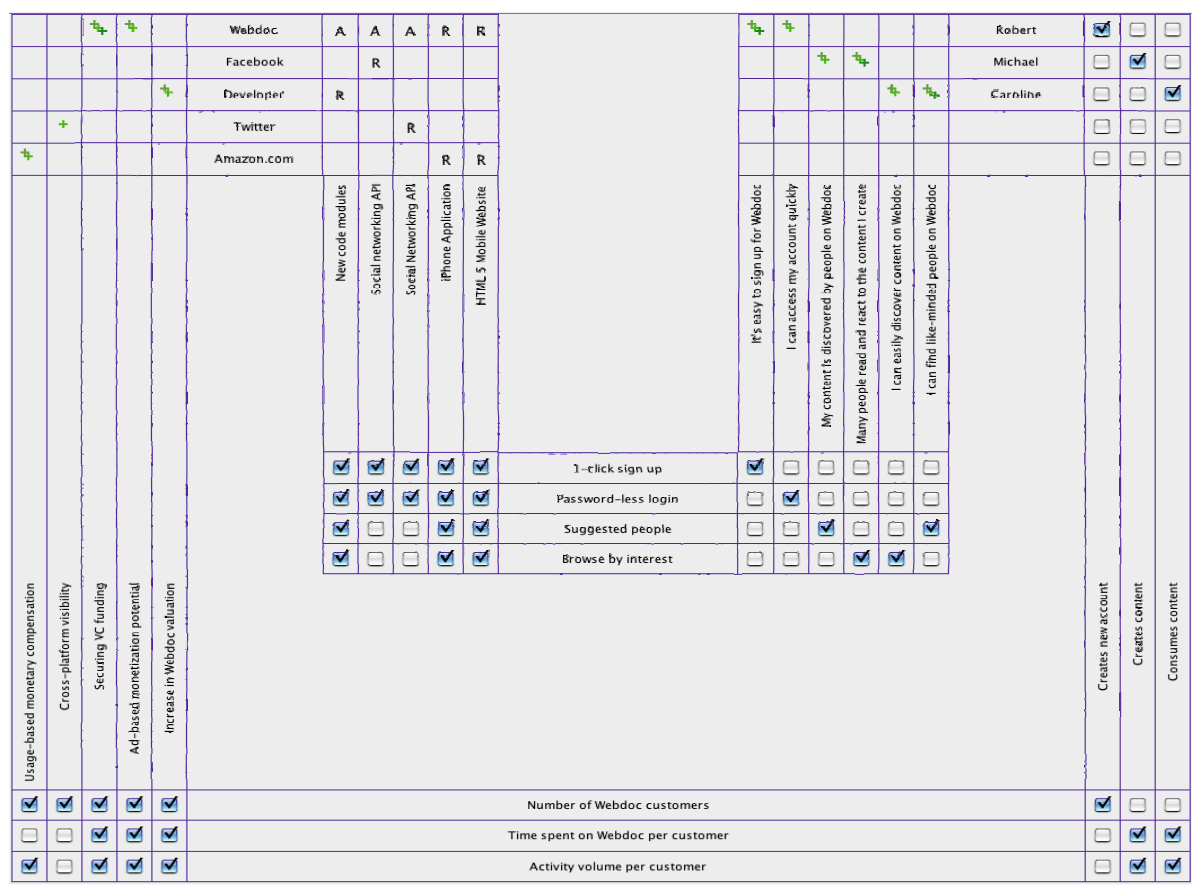

Fig. 5. The Value Map: capturing value creation and capture in Webdoc's service system 
The return visitors are divided into two main categories: content creators and content consumers.

- Content creators. This category of customers creates or curates the content on Webdoc. Curation is the process of sorting content created by others on the web and presenting it in a meaningful and organized way.

- Content consumers. These customers consume and react to the contents created by others. The reaction takes place in form of sharing, liking, or commenting on the contents.

It should be stated that these customer categories are not mutually exclusive.

As discussed in Section 2, the NPCV is impacted by the benefits and the costs of the service. As Webdoc offers its service to the customers free of charge, it would have been intuitive to focus on the service benefits to improve the NPCV. However, the findings from the data capture and user intelligence step revealed a number of improvement opportunities concerning the non-monetary costs of the service. As outlined in Table 2, these non-monetary costs include but are not limited to time, energy, and psychic aspects of adopting a service. Time cost is the aggregate of the durations the service customer needs to invest in order to be able to use the service. Energy cost is the sum of the effort that needs to be spent. Psychic cost is the most abstract of all - the cognitive stress undergone by the customer in using the service.

Data gathering and user intelligence aided us in mapping these three categories of non-monetary costs onto their corresponding value attributes (i.e., non-monetary costs of the service):

- Filling out the sign up form and discovering content and people increased the time and energy costs of the Webdoc's customers.

- Remembering passwords incurred Webdoc customers with high psychic costs.

\subsubsection{Improving Value Creation and Capture in Webdoc}

Figure 4 shows Webdoc's service system. The new actors and their properties are marked with the plus sign. In the Value Map in Figure 5, we illustrate how these novelties result in improving value creation and capture in Webdoc service system. We explain these changes in the following sections.

4.3.3.1 Reducing Clicks to Signup. Initially, an unregistered visitor needed to search for the sign up button, click it, and then fill out a form to complete the process. To save the visitor's time, the application programming interfaces (APIs) from social networking websites, Facebook and Twitter were integrated in the home page of Webdoc as shown in Figure 6. This way, the first-time visitors could sign up with one click without filling out the sign up form. The return visitors could also use their Facebook or Twitter credentials to connect to Webdoc.

As illustrated in the Value Map in Figure 5, Twitter and Facebook provide Webdoc with the APIs as the service components. These APIs along with the New code modules provided by the Developer result in the service features 1-click sign up and Password-less login. These two new features create the following two value attributes 


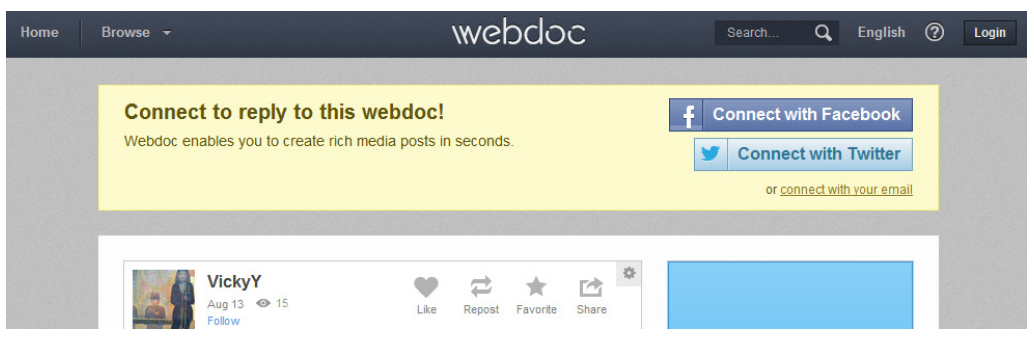

Fig. 6. Reducing clicks to sign up

for Robert who is a first-time visitor: It's easy to sign up for Webdoc and I can access my account quickly. These features along with the rest of the benefits of Webdoc convince Robert to create a new account (i.e., customer action) thereby increasing number of Webdoc customers increases. The rise in the number of customers contributes to Increase in Webdoc valuation, Ad-based monetization potential and Securing VC funding. As stated in Section 4.3.1, these are the main ways Webdoc can capture value. We can also see that Ad-based monetization potential is not as important as the other two value attributes. The number of Webdoc customers also gives Twitter and Facebook Cross-platform visibility, which can contribute to their web presence.

The two new service features improved the NPCV by reducing the time and energy costs associated with filling out the sign up form as well as the psychic costs of the remembering passwords. Introduction of these features increased the number of new accounts created on Webdoc. Moreover, nearly two months after their implementation, over $80 \%$ of the users were logging in to Webdoc using their Twitter and Facebook accounts.

4.3.3.2 Welcome Workflow. To facilitate discovering content and content creators, a welcome workflow was designed, see Figure 7.

As shown in the Value Map, the welcome workflow, captured in the New code modules service component, resulted in the creation of two new service features: Browse by interest and Suggested people.

Caroline is a content consumer. The two features help her in finding like-minded people and discovering content on Webdoc. Michael, a customer who creates content on Webdoc, benefits from these two features as his content is discovered by people on Webdoc and many people read and react to the content he creates. These value attributes form a self-reinforcing positive feedback loop. Michael creates content, which is discovered by Caroline. Caroline consumes Michael's content and reacts to it by commenting or liking or reposting his content. This motivates Michael to create or curate even more content. This virtuous cycle increases time spent on Webdoc per customer and activity volume per customer. These two non-monetary benefits contribute to Webdoc's value capture the same way as the number of Webdoc customers. When Webdoc's valuation increases some value is also captured by the developer who receives stock-based compensation. Finally, operating on the basis of a pay-per use pricing mechanism, Amazon.com also captures some value when the number of the customers and the activity per customer increase. 


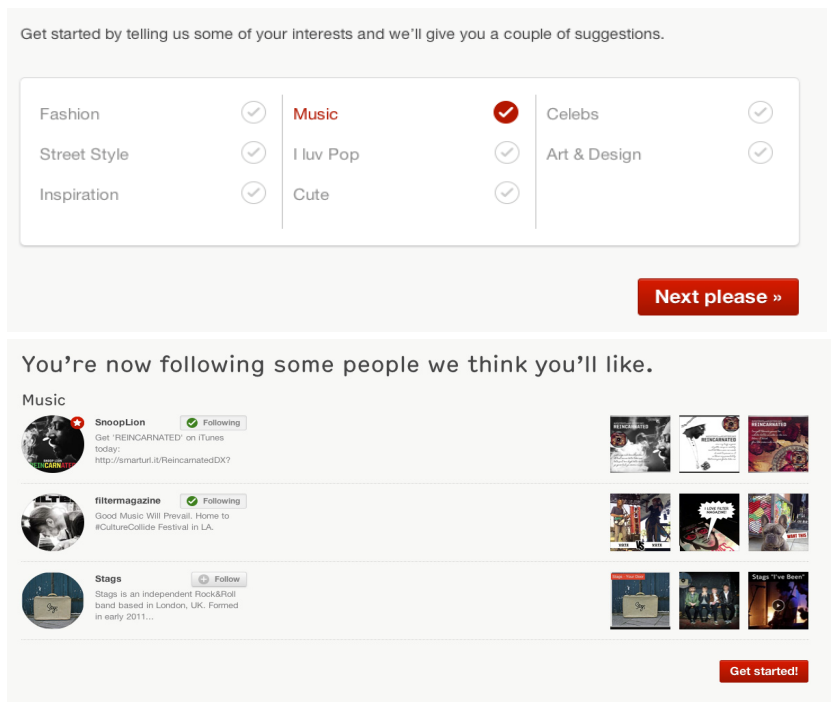

Fig. 7. Welcome workflow

The new features created by the welcome workflow reduce the energy and time costs pertinent to discovering people and content. The introduction of these two features contributed to the $250 \%$ increase in the log in rate of the Super Users, those customers of Webdoc who visit the website at least three times a week.

\subsection{Strategy Implications for Webdoc}

Over the past few months, Webdoc has improved the value its customers perceive from the services it offers, by reducing the non-monetary costs associated with its services. These improvements have resulted in an increase in the number of customers, the activity and the time spent by each customers. However, similar to any growth pattern there are limits to this growth.

We suggest that Webdoc should also become a platform to promote the work of the artists who are not famous. A young Sci-Fi writer, an unknown musician or a semiprofessional painter can be the potential new actors in Webdoc's service system. These people should not be merely seen as customers. In fact, they should be taken into account as parts of the Webdoc's value network. Expanding the value network results in the creation of a bigger pie for all the organizations and people involved and results in creating more value for customers.

\section{$5 \quad$ Related Work}

The Value Map is an extension to the SAR (Supplier Adopter Relationship) Diagram in [43, 44]. The Service System Model is based on the System Diagram [45]. The 
SAR and the System Diagram are parts of the Systemic Enterprise Architecture Methodology (SEAM) [46]. SEAM was designed from the ground up with general systems principles and serves to analyze and to assist in the design of business and engineering strategies. Developed at Ecole Polytechnique Fédérale de Lausanne (EPFL), SEAM has been used for teaching [44] and consulting [47].

In developing the Value Map, we are also inspired by the House of Quality [48], a quality improvement method, derived from Quality Function Deployment (QFD). We integrate the Strategy Canvas [49] as a part of the Value Map. Strategy Canvas is a diagnostic framework for strategy development. It enables an organization to visualize the competitive factors and the current state of play of those factors within a market place and to compare the organization's offering with those of the industry in general.

Business Model Canvas [24] is a strategic management tool, that assists in the development of new, and improvement of existing business models. It is widely recognized as one of the most established methods for business model design and innovation. The canvas represents value creation and capture in business models by nine building blocks: key partners, key activities, key resources, value propositions, customer relationships, channels, and customer segments. Business Model Canvas is one of the most established methods in the academia and industry for business model design, development and improvement.

\section{Empirical Study}

In this section, we elaborate on the empirical study that we conducted to assess the usefulness of The Value Map. In this study, we also compared the Value Map with Business Model Canvas [24]. Business Model Canvas is a strategic management tool, that assists in the development of new, and improvement of existing business models. The canvas represents value creation and capture in business models by nine building blocks: key partners, key activities, key resources, value propositions, customer relationships, channels, and customer segments. Business Model Canvas is one of the most established methods in the academia and industry for business model design, development and improvement.

We organized three workshops attended by 14 participants from Iran. The participants belonged to various industry sectors, such as automotive parts manufacturing, power generation, pharmaceutical and investment. They all held executive and senior management positions in their companies and had a minimum of 8 years of experience.

The first workshop lasted for 6 hours. In the first part of this workshop, we discussed business modeling and problem structuring in organizational decision processes. We also explained the theoretical concepts such as value creation and capture in business models. Then, we familiarized the participants with business model canvas and its nine building blocks. Next, we provided an example of a business model represented by the business model canvas. It should be noted that 5 participants were already familiar with the Business Model Canvas and/or applied it in representing a business model. 
In the second workshop that also lasted for 6 hours, we presented the Value Map, its underlying theoretical perspectives along with the example provided in this chapter. The participants were then divided in four groups. Each group decided on a business idea. In the groups where the members were from the same industry background a real business idea was chosen. The groups represented their business ideas first with the business model canvas and then the Value Map. We acted as facilitators during the sessions and answered to the participants' questions. When the models were completed and presented by the groups. During the presentation of the models, we provided feedback on the models to each group.

The third workshop was held a week after the second workshop lasted for three hours. We had asked the participants to reflect upon the usefulness, practicality and the potential merits of the Value Map and its positioning with respect to the Business Model Canvas. In the workshop, which lasted nearly 3 hours, we debriefed the participants. Some of them had tried to apply the Value Map in their organizations and shared their experiences with us.

At the end of the second workshop, a survey questionnaire was distributed among the participants. As shown in Figure 8, the participants had to specify whether they strongly disagree, disagree, are undecided about, agree or strongly agree with the nine statements. The first statement was on the importance of value creation and capture in the business model of an organization. Statements 2-5 were derived from the proposed future work by Osterwalder in [24: 141] "I propose that future work on business models includes testing the following hypotheses developed on the basis of the interviews with business practitioners:

- A business model ontology based visualization tool can help business practitioners more quickly understand a business model and the relationships behind its elements.

- A business model ontology based tool creates a common langue to address business model issues and in this regard improves communication between business practitioners.

- Discussing business model issues with a business model ontology based tool (to understand business models) has an impact on discussion quality."

In statements 6-9, we compare the Value Map and the business model canvas.

The results show that around $90 \%$ of respondents either agree or strongly agree with the statements. There is no proposition that is strongly rejected.

As presented in Table 4, all participants either agree or strongly agree on the importance of value creation and capture in the business model of an organization. This sheds light on the practical relevance of the topic of the research for the industry practitioners who participated in the survey.

Based on the responses to Statements 2 and 3, almost all of the participants found the Value Map a tool that can help them in understanding and analysis of value creation and capture by creating a common language that enables them to jointly represent, discuss the as-is situation and envision the to-be situation of the customer value creation and capture processes in the organization's business model. Over $85 \%$ of the participants agreed that the common language created by the Value Map 
SURVEY OF VALUE MAP, A PROBLEM STRUCTURING METHOD FOR VISUALIZING THE BUSINESS MODEL OF AN ORGANIZATION

\begin{tabular}{|l|l|l|}
\hline Name and Surname & \multicolumn{2}{|c|}{ Respondent's Signature } \\
\hline Organization & & \\
\hline Type of Business & & \\
\hline Organizational Position & \\
\hline Years of Experience & & \\
\hline
\end{tabular}

\begin{tabular}{|l|l|l|l|l|l|l|l|l|l|}
\hline 1 & Strongly disagree & 2 & Disagree & 3 & Undecided & 4 & Agree & 5 & Strongly Agree \\
\hline
\end{tabular}

\begin{tabular}{|c|c|c|c|c|c|c|}
\hline & & 1 & 2 & 3 & 4 & 5 \\
\hline 1 & Value creation and capture are central to an organization's business model. & & & & & \\
\hline 2 & $\begin{array}{l}\text { The Value Map helps business practitioners to understand and analyze customer value; customer } \\
\text { value creation, and the value capture processes in an organization's business model. }\end{array}$ & & & & & \\
\hline 3 & $\begin{array}{l}\text { The Value Map creates a common language for business practitioners that enables them to jointly } \\
\text { represent, discuss the as-is situation and envision the to-be situation of the customer value creation } \\
\text { and capture processes in the organization's business model. }\end{array}$ & & & & & \\
\hline 4 & $\begin{array}{l}\text { The Value Map facilitates and improves the communication among the business practitioners within } \\
\text { the organization. This improvement in communication positively impacts the quality of the discussions } \\
\text { regarding the business model of the organization. }\end{array}$ & & & & & \\
\hline 5 & $\begin{array}{l}\text { The Value Map is a useful visualization tool that contributes to managerial decision making processes } \\
\text { of business practitioners about the value creation and capture in an organization's business model. }\end{array}$ & & & & & \\
\hline 6 & Business Model Canvas helps identify the building blocks of an organization's business model. & & & & & \\
\hline 7 & $\begin{array}{l}\text { The two additional building blocks in the Value Map (i.e., the competing offers and, the service/product } \\
\text { features) are useful and/or necessary for representing an organization's business model. }\end{array}$ & & & & & \\
\hline 8 & $\begin{array}{l}\text { The Value Map models the inter-relations, inter-connections, linkages and the dynamics between the } \\
\text { building blocks of a business model. }\end{array}$ & & & & & \\
\hline 9 & $\begin{array}{l}\text { The Value Map complements and augments the Business Model Canvas by aiding the business } \\
\text { practitioners in representing the necessary building blocks of business model of an organization and } \\
\text { their inter-relations and interconnectedness. }\end{array}$ & & & & & \\
\hline
\end{tabular}

practitioners in representing the necessary but
their inter-relations and interconnectedness.

Fig. 8. The questionnaire

Table 4. Results of the survey - frequency of responses for statements in percentage

\begin{tabular}{lccccc}
\hline & $\begin{array}{c}\text { Strongly } \\
\text { Disagree }\end{array}$ & Disagree & Undecided & Agree & $\begin{array}{c}\text { Strongly } \\
\text { Agree }\end{array}$ \\
\hline Statement 1 & $0.0 \%$ & $0.0 \%$ & $0.0 \%$ & $28.6 \%$ & $71.4 \%$ \\
Statement 2 & $0.0 \%$ & $0.0 \%$ & $0.0 \%$ & $85.7 \%$ & $14.3 \%$ \\
Statement 3 & $0.0 \%$ & $7.1 \%$ & $0.0 \%$ & $57.1 \%$ & $35.7 \%$ \\
Statement 4 & $0.0 \%$ & $14.3 \%$ & $0.0 \%$ & $71.4 \%$ & $14.3 \%$ \\
Statement 5 & $0.0 \%$ & $14.3 \%$ & $7.1 \%$ & $64.3 \%$ & $14.3 \%$ \\
Statement 6 & $0.0 \%$ & $7.1 \%$ & $0.0 \%$ & $57.1 \%$ & $35.8 \%$ \\
Statement 7 & $0.0 \%$ & $0.0 \%$ & $0.0 \%$ & $28.6 \%$ & $71.4 \%$ \\
Statement 8 & $0.0 \%$ & $7.1 \%$ & $0.0 \%$ & $50.0 \%$ & $42.9 \%$ \\
Statement 9 & $0.0 \%$ & $0.0 \%$ & $0.0 \%$ & $50.0 \%$ & $50.0 \%$ \\
\hline
\end{tabular}

improves the communication among the business practitioners within the organization and thereby positively impacts the quality of the discussions by surfacing the practitioners' implicit assumptions regarding the business model of the organization. Finally, the majority of the participants came to the conclusion that the Value Map is a useful visualization tool that contributes to managerial decision making processes of business practitioners about the value creation and capture in an organization's business model. 
Based on the results reported in Table 4, the participants found the Business Model Canvas a useful method for identifying the building blocks of a business model. As stated earlier Business Model Canvas represents the business model by nine building blocks: key partners, key activities, key resources, value propositions, customer relationships, channels, and customer segments.

In the Value Map, we represent two building blocks additional to the ones conceptualized by the Business Model Canvas, namely: competing offerings and product/service offer features. The participants either strongly agree or agree that these two additional building blocks are useful and/or necessary for representing an organization's business model. The participants also concluded that Value Map models the interconnections between the building blocks of a business model, whereas the Business Model Canvas just aims at identifying these building blocks. Finally based on the responses to Statement 9 we can state that participants thought that the Value Map can complement and augment the Business Model Canvas by representing the necessary building blocks of business model of an organization and their inter-relations.

Table 5 illustrates a summary of the statistics of the survey. As shown, the average (mean) of the responses to the statements is 4.27 which means the participants either agree or strongly agreed with all the statements. The standard deviation for all the statements is 0.67 , which is relatively small with negative skewness values.

Table 5. Summary of the statistics of the survey

\begin{tabular}{lcccc}
\hline & Mean & Median & STD & Skewness \\
\hline Statement 1 & 4.71 & 5.00 & 0.469 & -1.067 \\
Statement 2 & 4.14 & 4.00 & 0.363 & 2.295 \\
Statement 3 & 4.21 & 4.00 & 0.802 & -1.482 \\
Statement 4 & 3.86 & 4.00 & 0.864 & -1.361 \\
Statement 5 & 3.79 & 4.00 & 0.893 & -1.035 \\
Statement 6 & 4.21 & 4.00 & 0.802 & -1.482 \\
Statement 7 & 4.71 & 5.00 & 0.469 & -1.067 \\
Statement 8 & 4.29 & 4.00 & 0.825 & -1.583 \\
Statement 9 & 4.50 & 4.50 & 0.519 & 0 \\
\hline
\end{tabular}

To sum up, based on the debriefing in the third workshop, the participants found the Value Map a useful visualization tool that can contribute to the decision processes that require competitor analysis, understanding customer needs and preferences and the features of the product or service that needs to be designed or improved to meet and fulfil the customer needs. Some of the participants stated that the Value Map can be of great value for cross functional teams and when applied for organizational diagnosis. The discussions with the participants also revealed a number of improvement opportunities in terms of adding a quantitative model, simplifying the graphical representation, and the parsimoniousness of the conceptualizations.

Some of the improvement opportunities mentioned by the participants are already taken into account in the instantiation of the Value Map in the 
www.tradeyourmind.com online platform. For instance, the inclusion of the quantitative models that can generate numerical analyses of various value creation and capture strategies is part of the platform. The step-by-step model generation wizard embedded in the www.tradeyourmind.com platform also facilitates the development and the presentation of the Value Map. We will try to address the remaining points in our future work.

The participants also commented on the relationship between the Value Map and the Business Model Canvas. They were unanimous that the representations created by Business Model Canvas can be used as an input to the Value Map. In other words, the Value Map makes explicit the relationships between the building blocks of a business model represented in the Business Model Canvas.

\section{Conclusions}

In this paper, we introduced the Value Map as a problem structuring method (PSM) that aids in conceptualization and representation of value creation and capture in service systems. The Value Map is grounded in the theoretical insights from economics, management science and (services) marketing literature, drawing principally upon work from the past two decades on value creation and capture, including theories, frameworks, constructs, and other models. We illustrated the usability and applicability of our framework by modeling value creation and capture in Webdoc's service system. We also briefly presented the results of a survey conducted to assess the usefulness of Value Map and compare it with Business Model Canvas.

This research suffers from a number of limitations. We used data synthesized in a single case study to illustrate the applicability of the Value Map. Despite the fact that the data for the case study was gathered from a project we conducted in a company, we believe we need to apply the Value Map in several other contexts to be able to fully assess the practical relevance of its representations. Thus, in our future work we will focus on applying the Value Map in a number prospective business cases. This will definitely result in a better evaluation of the applicability of the Value Map.

The second limitation of this research concerns the empirical study we conducted to evaluate the usefulness of the Value Map. The fact that all the participants in the survey were from Iran and the relatively small sample size limit the generalizability of the findings of our research. To tackle this limitation, the same study should be conducted among executives and managers from different countries.

Lastly, the articles based on which the conceptualizations underlying the Value Map were developed are not exhaustive. Despite the fact that we synthesized over 30 well-cited articles on value creation and capture that were to the best of our knowledge seminal to the field, some relevant work still may not have been included in the review of the literature. Inclusion of such articles can bring in new modeling constructs or fine-tune and improve the existing constructs in the Value Map. Refining our conceptualizations based on the existing work that has not been included in the study will also be a part of our future work. 


\section{References}

1. Prahalad, C., Ramaswamy, V.: Co-creation Experiences: The Next Practice in Value Creation. Journal of Interactive Marketing 18(3) (2004)

2. Vargo, S.L., Lusch, R.F., Akaka, M.A.: Advancing Service Science with ServiceDominant Logic - Clarifications and Conceptual Development. In: Handbook of Service Science, pp. 133-156 (2010)

3. Vargo, S.L., Lusch, R.F.: Service-Dominant Logic: Continuing the Evolution. Journal of the Academy of Marketing Science 36(1), 1-10 (2008)

4. Vargo, S.L., Lusch, R.F.: Evolving to a New Dominant Logic of Marketing. Journal of Marketing 68(1), 1-17 (2004)

5. Vargo, S.L., Maglio, P.P., Akaka, M.A.: On Value and Value Co-creation: A Service Systems and Service Logic Perspective. European Management Journal 26, 145-152 (2009)

6. Sphorer, J., Maglio, P.: The Emergence of Service Science: Toward systematic service innovations to accelerate co-creation of value. Production and Operations Management (2008)

7. Grönroos, C.: Service marketing: a study of the marketing function in service firms (In Swedish with an English summary). Diss. Helsinki and Stockhold, Hanken Swedish School of Economics, Marketing Technique Centre and Akademilitteratur, Helsinki (1979)

8. Grönroos, C.: Adopting a service logic for marketing. Marketing Theory 6(3), 317-333 (2006)

9. Grönroos, C.: Service logic revisited: who creates value? And who co-creates? European Business Review 20(4), 198-314 (2008)

10. Ballantyne, D., Varey, R.J.: Creating value-in-use through marketing interaction: the exchange logic of relating, communicating and knowing. Marketing Theory 6(3), 335-348 (2006)

11. Gummesson, E.: Exit services marketing - enter service marketing. Journal of Customer Behaviour 6(2), 113-141 (2007)

12. Sandström, S.E., Kristensson, P.: Value in use through service experience. Managing Service Quality 18(2), 112-126 (2008)

13. Lusch, R.F., Vargo, S.L.: The Service-Dominant Logic of Marketing: Dialog, Debate, and Directions. M. E Sharpe, Armonk (2006)

14. Lepak, D.P., Smith, K.G., Taylor, M.S.: Value Creation and Value Capture: A Multilevel Perspective. Academy of Management Review 32(1), 180-194 (2007)

15. Bowman, C., Ambrosini, V.: Value Creation Versus Value Capture: Towards a Coherent Definition of Value in Strategy. British Journal of Management 11(1), 1-15 (2000)

16. Parasuraman, A., Zeithaml, V.A., Berry, L.: A Conceptual Model of Service Quality and Its Implications for Future Research. Journal of Marketing 49, 41-50 (1985)

17. Ritala, P., Hurmelinna-Laukkanen, P.: What's in it for me? Creating and appropriating value in innovation-related coopetition. Technovation 29(12), 819-828 (2009)

18. Gordijn, J., Akkermans, J.: Value-based requirements engineering: Exploring innovative e-commerce ideas. Requirements Engineering 8(2), 114-134 (2003)

19. Weigand, H., Johannesson, P., Andersson, B., Bergholtz, M.: Value-based service modeling and design: Toward a unified view of services (2009)

20. Pijpers, V., Gordijn, J.: e 3 forces: Understanding Strategies of Networked e 3 value Constellations by Analyzing Environmental Forces Advanced Information Systems Engineering, 188-202 (2007) 
21. Yu, E.S.K.: Towards modelling and reasoning support for early-phase requirements engineering. Paper Presented at the The Third IEEE International Symposium on Requirements Engineering (1997)

22. Weigand, H.: Value EncountersñModeling and Analyzing Co-creation of Value. Software Services for e-Business and e-Society, 51-64 (2009)

23. Mingers, J., Rosenhead, J.: Problem structuring methods in action. European Journal of Operational Research 152(3), 530-554 (2004)

24. Rosenhead, J.: What's the problem? An introduction to problem structuring methods. Interfaces 26, 117-131 (1999)

25. Rosenhead, J., Mingers, J.: Rational analysis for a problematic world revisited. John Wiley and Sons, Chichester (2001)

26. Osterwalder, A., Pigneur, Y.: Business model generation: A handbook for visionaries, game changers, and challengers. Wiley, New York (2010)

27. Hart, C.: Doing a literature review: Releasing the social science research imagination. Sage Publications Limited (1999)

28. Whetten, D.A.: What constitutes a theoretical contribution? Academy of Management Review 14(4), 490-495 (1989)

29. Baker, M.J.: Writing a literature review. The Marketing Review 1(2), 219-247 (2000)

30. Kotler, P.: Marketing management, millennium ed. (2000)

31. Day, G.S.: Market - Driven strategy: Processes for Creating Value. The Free Press, New York (1990)

32. Huber, F., Herrmann, A., Morgan, R.E.: Gaining competitive advantage through customer value oriented management. Journal of Consumer Marketing 18(1), 41-53 (2001)

33. Grönroos, C.: Service Management and Marketing. European Journal of Marketing 15, $3-31(2000)$

34. Kothandaraman, P., Wilson, D.T.: The Future of Competition: Value-Creating Networks. Industrial Marketing Management 30(4), 379-389 (2001)

35. Moller, K., Svahn, S.: Role of Knowledge in Value Creation in Business Nets*. Journal of Management Studies 43(5), 985-1007 (2006)

36. Pynnonen, M., Ritala, P., Hallikas, J.: The new meaning of customer value: A systemic perspective. Journal of Business Strategy 32(1), 51-57 (2011)

37. Nelson, R.R., Winter, S.G.: An evolutionary theory of economic change. Belknap Press (1982)

38. Allee, V.: Value network analysis and value conversion of tangible and intangible assets. Journal of Intellectual Capital 9(1), 5-24 (2008)

39. Ulaga, W.: Capturing value creation in business relationships: A customer perspective. Industrial Marketing Management 32(8), 677-693 (2003)

40. Masten, S.E., Meehan, J.W., Snyder, E.A.: The costs of organization. Journal of Law, Economics, and Organization 7(1), 1 (1991)

41. Blomqvist, K., Kylaheiko, K., Virolainen, V.M.: Filling a gap in traditional transaction cost economics: Towards transaction benefits-based analysis. International Journal of Production Economics 79(1), 1-14 (2002)

42. Carson, R.T., Flores, N.E., Martin, K.M., Wright, J.L.: Contingent valuation and revealed preference methodologies: Comparing the estimates for quasi-public goods. Land Economics, 80-99 (1996)

43. Indvik, L.: Facebook Completes \$730 Million Instagram Acquisition (2012), http: / /mashable.com/2012/09/06/facebook-instagramacquisition-complete/ (retrieved May 2013) 
44. Bhide, A.: The origin and evolution of new businesses. Oxford University Press on Demand (2000)

45. Golnam, A., Regev, G., Ramboz, J., Laprade, P., Wegmann, A.: Systemic Service Design: Aligning Value and Implementation. In: Morin, J.-H., Ralyté, J., Snene, M. (eds.) IESS 2010. LNBIP, vol. 53, pp. 150-164. Springer, Heidelberg (2010)

46. Wegmann, A., Julia, P., Regev, G., Perroud, O., Rychkova, I.: Early Requirements and Business-IT Alignment with SEAM for Business. Paper presented at the 15th IEEE International Requirements Engineering Conference (RE 2007), Delhi, India (2007)

47. Rychkova, I., Regev, G., Le, L.-S., Wegmann, A.: From Business To IT with SEAM: The J2EE Pet Store Example. Paper presented at the 11th IEEE International Conference on Enterprise Distributed Object Computing, EDOC 2007 (2007)

48. Wegmann, A.: On the systemic enterprise architecture methodology (SEAM). Paper presented at the International Conference on Enterprise Information Systems, Angers, France (2003)

49. Wegmann, A., Regev, G., Loison, B.: Business and IT alignment with SEAM. Proceedings of the 1st International Workshop on Requirements Engineering for Business Need, and IT Alignment, Paris, France (2005)

50. Clausing, D., Hauser, J.R.: The house of quality. Harvard Business Review 66, 63-73 (1988)

51. Kim, W.C., Mauborgne, R.E.: Blue Ocean Strategy: How to Create Uncontested Market Space and Make Competition Irrelevant. Harvard Business Press (2005) 